Nutrition and older people:

special considerations relating to nutrition

\section{and ageing}

Salah Gariballa MD FRCP, Clinical Senior Lecturer, University of Sheffield and Barnsley Hospital

Clin Med 2004;4:411-4

The number of people aged over 65 in England has more than doubled since the now over 60 (Fig 1). ${ }^{1}$ Good nutrition contributes to the health and well-being of elderly people and to their ability to recover from illness. With advancing age, both undernutrition and chronic diseases become more common. Poor nutrition may lead to ill health, and ill health to poor nutrition, so identifying priorities for management remains a challenge. $^{2}$

\section{Age-related physiological and pathological changes relevant to nutrition}

\section{Physiological changes}

Anorexia and weight loss are common and important clinical problems in the elderly and may lead to clinically relevant 1930s and a fifth of the population is undernutrition, but the mechanisms are poorly understood. ${ }^{3}$

Gastrointestinal system: alteration in smell and taste and poor dental health directly decrease food intake and/or influence food selection. In 1995 more than $70 \%$ of over $65 \mathrm{~s}$ in England and Wales were edentulous. In addition, age-related achlorhydria can impair absorption of micronutrients. ${ }^{2}$

Physical activity: ageing is associated with decrease in physical activity and lean body mass and an increase in body fat, in turn decreasing energy requirements and intake. ${ }^{2}$ Lower food intake leads to lower intakes of micronutrients and macronutrients, so increasing nutrient density of the diet is required to maintain adequate micronutrient intake.

\section{Pathological changes}

Medical and social factors: decreased visual acuity, joint problems, hand tremors and hearing problems in combination may hinder food preparation and eating, but may respond to treatment. Other risk factors include isolation, with

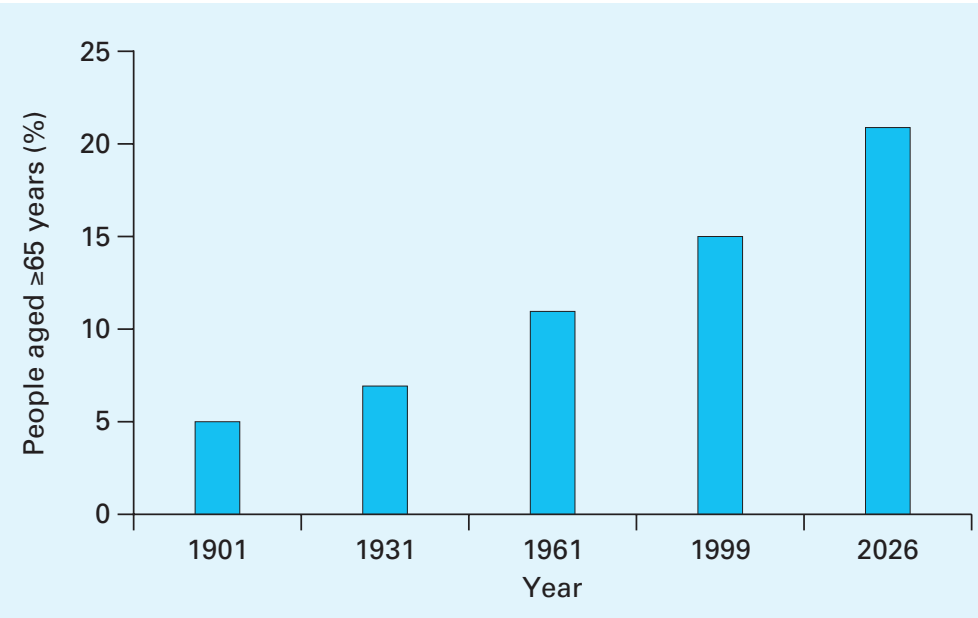

Fig 1. Percentage of people aged 65 years and over in the UK population (1901-2026). an inability to go out shopping, loss of spouse, depression, decreased mobility, dementia and anorexia due to disease, medications, poor dentition, alcoholism and acute illness. ${ }^{2}$

Drug interactions: changes in body composition with ageing may influence drug metabolism. For example, the fall in lean body mass and body water reduces the volume of distribution of water-soluble drugs (eg digoxin), while the increase in body fat increases that of fat-soluble drugs (eg diazepam). As well as the possible effects of illness on nutritional status, many drugs, which are commonly used in the elderly, may have specific interaction with nutrition factors such as:

- energy intake and appetite (corticosteroids, metformin, digoxin, tricyclic antidepressants, anticancer drugs)

- vitamin status (isoniazid, methotrexate, cholestyramine), or

- minerals and electrolytes (diuretics, non-steroidal anti-inflammatory drugs).

Immune function: undernutrition contributes to age-related immune dysregulation, with decreased lymphocyte proliferation and cytokine release and lower antibody response to vaccines. Low intake of micronutrients, including zinc, selenium, iron, copper, vitamins A, C, E and B6, and folic acid which influence immune function, are common in aged populations. ${ }^{4}$

Cognitive function: deficiencies of folate and vitamins B2, B6 and B12 are associated with loss of cognitive function and dementia in older people, although there are doubts about whether the micronutrient defect leads to functional loss or vice versa, or both. Severe deficiencies are rare but milder deficiencies are not uncommon.

Obesity is associated with a range of health problems and affects an increasing number of people across all ages. The incidence of diseases associated with obesity such as hypertension, type 2 diabetes, atherosclerosis, arthritis and disability increases with age. 


\section{Key Points}

Provided that individual elderly people stay in good health, their dietary intakes are not likely to be that much different from those of younger age

Older people are at risk of malnutrition due to reduced activity and food intake, body composition changes, physical and mental illness, disability and lack of mobility

Most 'pathological' factors associated with ageing such as social, psychological, physical and medical factors, which may predispose to malnutrition are responsive to treatment

Older people should be advised to eat a balanced diet containing a variety of nutrient-dense foods, more fruits, vegetables and grains, foods containing adequate amounts of calcium and vitamin D. This may need to be monitored in some individuals

Elderly people should be encouraged to lead an active life, especially after episodes of intercurrent illness

All older people accessing the health services should be nutritionally screened using the MUST tool

Dietetic advice is an integral part of the management of older people in hospital. It should be sought early to assess the most appropriate method of meeting individual nutritional requirements in those patients at risk, and to provide advice for nursing and medical staff, catering and other health professionals involved

Dietary treatment strategies should be tailored to meet the needs and preferences of individual patients. They should also be flexible, responsive and reviewed on a regular basis to maintain enthusiasm and commitment

KEY WORDS: ageing, clinical outcome, chronic disease, elderly patients, macronutrients, micronutrients, nutritional support, older people, undernutrition

\section{Micronutrients}

\section{$B$ group vitamins and homocysteine}

Deficiencies of folate or vitamins B6 or B12 increase plasma homocysteine concentrations. Hyperhomocysteinaemia shows an independent graded association with vascular disease and is a strong predictor of both cardiovascular and non-cardiovascular mortality in older people. ${ }^{5}$ It remains to be established whether it is causal. The prevalence of hyperhomocysteinaemia in the general population is $5-10 \%$ but as high as $30-40 \%$ in the elderly population.

\section{Antioxidants}

One theory of the ageing process is that oxygen free radicals lead to cumulative damage to cellular structure and function. Free radical damage may be important in conditions such as
Parkinson's and Alzheimer's diseases, chronic inflammatory disease, cardiovascular disease and cancer. There is evidence that the risk of cardiovascular disease and some cancers may be reduced by high consumption of fruits, wholegrains and vegetables, ${ }^{6}$ but antioxidant nutrient supplements such as vitamins $\mathrm{C}, \mathrm{E}$ and $\beta$-carotene show no benefit.

\section{Calcium and vitamin $D$}

Age-related renal impairment may decrease the renal hydroxylation of 25-hydroxyvitamin $\mathrm{D}$ to active 1,25dihydroxyvitamin D. Up to $50 \%$ of the elderly have inadequate vitamin D status due to sunlight deprivation, decreased intake of meat and dairy products and malabsorption.

Bone mass declines with age, leading to osteoporosis and increased fracture risk. Combined calcium and vitamin D supple- mentation can reduce femoral neck and spine bone loss and also the incidence of non-vertebral fractures in older people. ${ }^{7}$ It is recommended that all vulnerable older people take a supplement of $10 \mu \mathrm{g}$ of vitamin $\mathrm{D}$ daily.

\section{Zinc}

Institutionalised elderly subjects are at increased risk of zinc deficiency which adversely affects cellular immunity at all ages. Zinc promotes healing of damaged tissues, especially skin in those who are zinc deficient.

\section{Nutritional status of older people}

\section{In the community}

Mean reported daily energy intake in 1995 for free-living men aged 65 years and over was 1,909 Kcal and for women $1,422 \mathrm{Kcal}$, but these may be underestimates due to underreporting. Free-living men, but not women, who were unwell and whose eating was affected had lower intakes of vitamins $\mathrm{A}$ and $\mathrm{D}$, pantothenic acid and riboflavin, and lower intakes per unit of energy of retinol, vitamins $B_{12}$ and D. ${ }^{8}$

\section{In acute and non-acute care settings}

The effect of ill health on the nutritional status of hospitalised patients is not limited to the time of acute illness. After recovery or discharge, elderly people remain vulnerable because of decreased nutritional reserves and repeated episodes of ill health. Undernutrition is prevalent and unrecognised in elderly people on admission and is associated with increasing morbidity and mortality. Nutritional status often deteriorates throughout their hospital stay and persists following discharge into the community. ${ }^{2,9,10}$ Nutritional screening on admission and in the community using the MUST tool (see article on nutrition in acute care in this series) is important. If necessary, assistance should be provided to elderly patients in making the right food choices and in feeding. Priority 
should be given to meal times, supervision should be available and patients allowed enough time to eat.

\section{Why do older patients need nutritional support and when?}

Elderly patients are likely to have poor nutritional status prior to hospital admission. This may be associated with impaired immune function and is likely to deteriorate further as the result of acute illness. Nutritional depletion may worsen during rehabilitation which may extend over weeks and months. Poor nutritional status in ageing patients has prognostic significance and is more amenable to therapy during convalescence/rehabilitation than in the acute phase of illness. ${ }^{10}$

\section{Nutritional support of older people}

Nutritional supplements given orally or enterally can improve outcomes for people aged 65 years or older. For example, vitamins and trace elements supplementation significantly improves immunity and decreases the risk of infection. ${ }^{11}$ A systematic review found that in elderly people at risk of malnutrition, supplementation of protein and energy improved mortality (relative risk 0.67 , 95\% confidence interval (CI) 0.52-0.87) and shortened hospital stay ( -3.4 days, 95\% CI -6.12 to -0.69$)$. However, few data were reported and most studies were too short to detect differences in morbidity, functional status and quality of life. ${ }^{12}$

\section{Undernutrition of special elderly patient groups}

\section{Elderly stroke patients}

Stroke produces a wide range of possible functional deficits such as difficulties in swallowing, hemiplegia, impaired consciousness, perceptual deficits and visual field defects. These have variable impacts on a stroke patient's nutrient demands and intake. Undernutrition is associated with increased morbidity and mortality in stroke patients. ${ }^{9,13}$

\section{Elderly patients with chronic obstructive pulmonary disease}

Undernutrition is associated with impaired lung function among patients with chronic obstructive pulmonary disease (COPD). It is unclear whether undernutrition is the cause of deterioration in these patients or a result of respiratory failure, or a combination. Treating malnutrition in COPD may improve body composition, muscular strength and respiratory function. ${ }^{14} \mathrm{~A}$ metaanalysis failed to demonstrate an effect of at least two weeks' energy and protein supplementation on anthropometric measures, lung function or functional exercise capacity in patients aged 65 years or over. ${ }^{15}$

\section{Dementia}

Undernutrition in dementia patients may be caused by many factors, including decreased food intake due to anorexia, dysphagia or inability to feed. Increased energy expenditure might occur in wandering and in agitated patients, which may further exacerbate weight loss and wasting.

\section{Parkinson's disease}

Patients with Parkinson's disease are vulnerable to nutritional deficiencies both because of decreased food intake due to anorexia, depression, dysphagia or inability to feed and because of increased energy expenditure due to hypertonicity, tremor and drug treatment. Patients with Parkinson's disease tend to lose weight, have less body fat and lower plasma levels of iron, zinc, vitamins $\mathrm{E}$ and $\mathrm{A}$ than control subjects.

\section{Elderly patients with hip fracture}

Up to half the elderly patients who suffer hip fractures are undernourished. Insufficient nutrient intake can contribute both to osteoporosis and to falls - important causes of fractures. A meta-analysis in patients with hip fracture aged over 65 reported that nutritional supplementation with oral protein and energy feeds improved mortality and long-term complications, but trials of intravenous thiamine, other watersoluble vitamins and vitamin D showed no benefit. ${ }^{16}$

\section{References}

1 Population: by gender and age 1901-2026. Social Trends 31 (ST 31103). London: Office for National Statistics, 2001.

2 Gariballa SE, Sinclair AJ. Nutrition, ageing and ill-health. Review. Br J Nutr 1998;80: 7-23.

3 MacIntosh CG, Morley JE, Chapman IM. The anorexia of aging. Review. Nutrition 2000;16:983-95.

4 Lesourd BM. Nutrition and immunity in the elderly: modification of immune responses with nutritional treatments. Am J Clin Nutr 1997;66:478S-84S.

5 Vollset SE, Refsum H, Tverdal A, Nygard O et al. Plasma total homocysteine and cardiovascular and noncardiovascular mortality: the Hordaland Homocysteine Study. Am J Clin Nutr 2001;74:130-6.

6 Gariballa SE. Nutrition and stroke: prevention and treatment. Oxford: Blackwell Publishing Ltd, 2004.

7 Dawson-Hughes B, Harris SS, Krall EA, Dallal GE. Effect of calcium and vitamin D supplementation on bone density in men and women 65 years of age and older. N Engl J Med 1997;337:670-6.

8 Finch S, Doyle W, Lowe C, Bates C et al. National Diet and Nutrition Survey: people aged 65 years and over, vol 1. Report of the Diet and Nutrition Survey, 1998.

9 FOOD Trial Collaboration. Poor nutritional status on admission predicts poor outcome after stroke: observational data from the FOOD trial. Stroke 2003;34:1450-6.

10 Gariballa SE. Editorial comment: Proteinenergy undernutrition and acute stroke outcome. Stroke 2003;34:1455-6.

11 Chandra RK. Effect of vitamin and trace-element supplementation on immune responses and infection in elderly subjects. Lancet 1992;340:1124-7.

12 Milne AC, Potter J, Avenell A. Protein and energy supplementation in elderly people at risk from malnutrition. Cochrane Database Syst Rev, issue no. 3, 2002.

13 Gariballa SE, Parker SG, Taub N, Castleden $\mathrm{CM}$. Influence of nutritional status on clinical outcome after acute stroke. Am J Clin Nutr 1998;68:275-81.

14 Akner G, Cederholm T. Treatment of protein-energy malnutrition in chronic nonmalignant disorders. Review. Am J Clin Nutr 2001;74:6-24.

15 Ferreira IM, Brooks D, Lacasse Y, Goldstein RS. Nutritional support for individuals with COPD: a meta-analysis. Chest 2000;117: 672-8. 


\section{CME Nutrition}

16 Avenell A, Handoll HH. Nutritional supplementation for hip fracture aftercare in the elderly. Review. Cochrane Database Syst Rev 2004; CD001880.

\section{Nutrition SELF-ASSESSMENT QUESTIONNAIRE}

\section{SAQs - and answers - are now ONLINE for RCP Fellows and Collegiate Members}

From this volume onwards, the SAQs printed in the CME section can be answered online to achieve External CPD credits

\section{The answering process}

1. To access the questions, log on to the Fellows and Members area http://www.rcplondon.ac.uk/Members/SAQ (those who have not yet registered will be automatically directed to the registration pages)

2. Select: Online learning $S A Q$

3. At the top of the $S A Q$ page select the current $C M E$ question paper

4. Answer all 10 questions in any order, by indicating true or false

5. Check your answers and change them if you wish to

6. Click on Submit for final marking.

(Note - after submitting your answers NO changes are possible)

\section{The marking process}

n You must submit the answers before the closing date shown at the top of the screen

- Answers will be marked automatically on the date displayed for that paper

- You can find your marks with explanations of the answers on the CME page under My past CME papers

\section{Registering your External CPD credits}

A pass mark of $80 \%$ allows you to claim 2 External CPD credits. Thus by answering the SAQs in each issue of Clinical Medicine you can achieve 12 external credits in one year.

To claim your credits:

- Online registrants: You can record your credits using the online diary system. All Clinical Medicine SAQs are listed under External Approved CPD

- Manual registrants: You can record your credits using your paper diary sheets. Manual registrants are required to keep evidence of their participation in the SAQ and the score attained.

Please note that past papers will be stored for 12 months. 